\title{
SPECIAL
}

ARTICLES

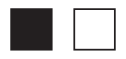

\section{The Time Is Now: A Plan to Redesign Family Medicine Residency Education}

Larry A. Green, MD; William L. Miller, MD, MA; John J. Frey, III, MD; Hilliard Jason, MD, EdD; Jane Westberg, PhD, MA; Deborah J. Cohen, PhD; Robin S. Gotler, MA; Frank V. DeGruy, MD

\begin{abstract}
A new graduate medical education program in family medicine is urgently needed now. We propose an innovative plan to develop community-based, community-owned family medicine residency programs. The plan is founded on five guiding principles in which residencies will (1) transition to independent, community-owned organizations; (2) sustain comprehensiveness and generalism; (3) emphasize collaborative learning and interprofessional education; (4) develop local educators with national guidance; and (5) share resources, responsibilities, and learning. We describe actionable steps to begin the process of transforming residencies and strengthening primary care. As community-based and locally-run organizations, residencies will gain self-determination in how time is allocated, budgets are spent, and teams function. Building on the momentum of the National Academy of Medicine's 2021 primary care implementation plan and recommendations by family medicine organization leaders, we propose a Decade of Family Medicine Residency Transformation. We encourage individuals and organizations spanning disciplines, health care systems, and communities, to join forces to reimagine and recreate the preparation of outstanding personal physicians dedicated to individual and community health and well-being.
\end{abstract}

(Fam Med. 2022;54(1):7-15.)

doi: 10.22454/FamMed.2022.197486

"We shall not cease from exploration And the end of all our exploring Will be to arrive where we started And know the place for the first time."

-T.S. Eliot ${ }^{1}$

$\mathbf{N}$ ow is the time for significant change in family medicine postgraduate education. ${ }^{2-4}$ With new family medicine accreditation requirements underway, this is the moment to go beyond small steps. It is time to take substantial and meaningful leaps forward, as family medicine undertakes its most important and exciting transformation since the specialty was established.

The need is clear. The design of today's family medicine residencies follows a template that is decades old, time-focused and hospital-centric, emphasizing standardization over flexibility and innovation. The result is an imbalance between the structure and content of residency education and the competencies required to meet the ever-evolving, widely diverse needs of patients, families, communities, health care systems, and family physicians themselves.

This article describes a new direction for family medicine graduate medical education, building on recent recommendations for "reenvisioning family medicine residency education." ${ }^{4}$ In keeping with the 2021 National Academies of Medicine, Engineering and Science report that identifies primary care as a common good, ${ }^{5}$ we propose a community-based, community-owned residency program (Figure 1) founded on five guiding principles. These principles support critical primary care functions (ie, the "7 Cs": first Contact, Continuity, Comprehensiveness, Coordination, Community engagement, patient-Centeredness, Complexity), and the " $4 \mathrm{Ts}$ " that facilitate them (Team-based, Tool- and Technology-enabled, Tailored care) ${ }^{6}$ We describe action steps to transform residencies and strengthen primary care's ability to improve individual, family, community, and national health. Innovations will be based on local needs and community strengths. As community-based and locally-run organizations, residencies will gain self-determination in how time is allocated, budgets are

From the Department of Family Medicine, University of Colorado School of Medicine, Denver, CO (Drs Green, Jason, Westberg, and DeGruy); Department of Family Medicine, Lehigh Valley Health Network, Allentown, PA (Dr Miller); Department of Family Medicine, University of Wisconsin School of Medicine, Madison, WI (Dr Frey); iMedtrust, London, United Kingdom (Drs Jason and Westberg); Department of Family Medicine, Oregon Health and Science University, Portland, OR (Dr Cohen); and Center for Community Health Integration, Case Western Reserve University School of Medicine, Cleveland, OH (Ms Gotler). 
Figure 1: A New Community-Based, Community-Owned Residency Program

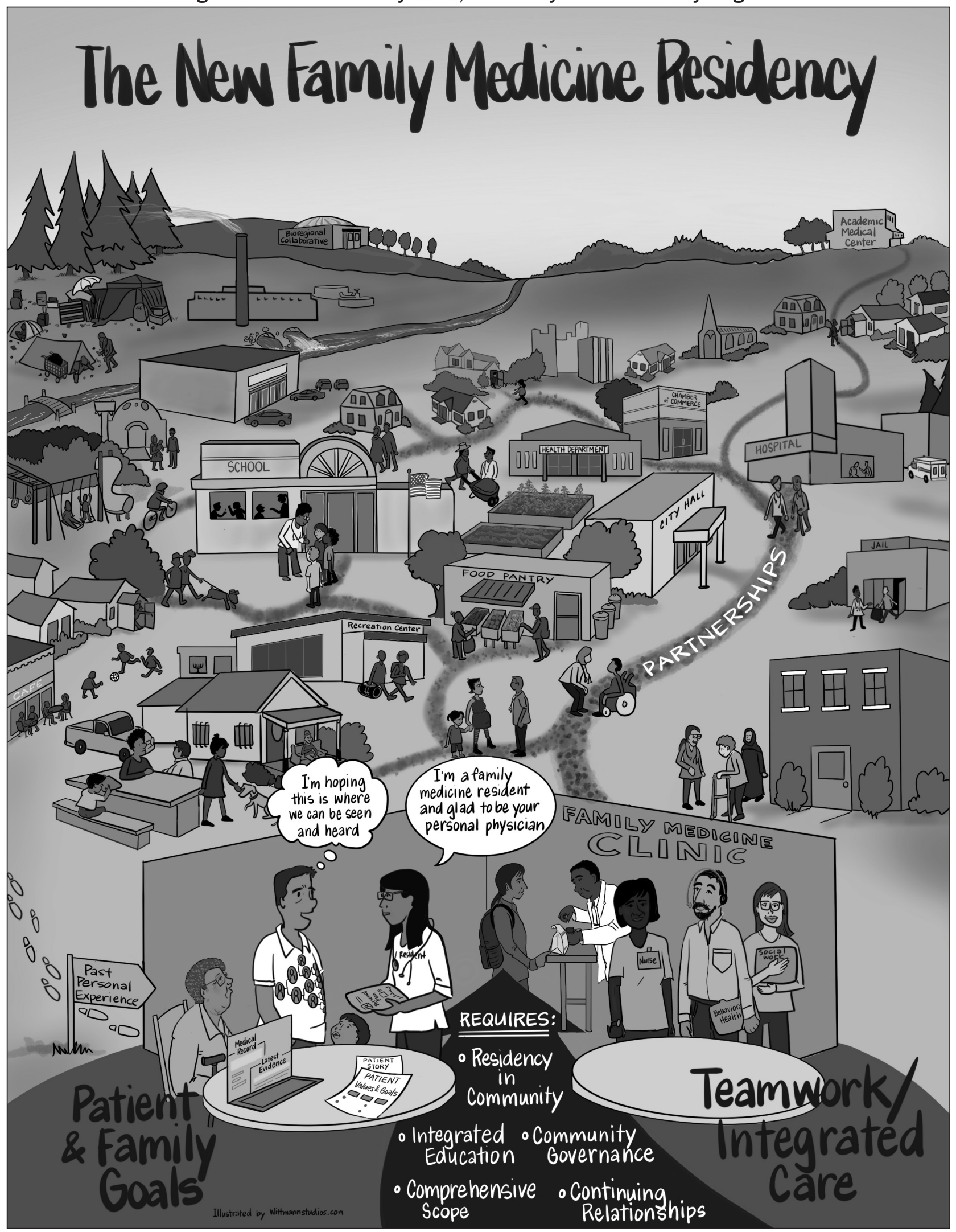

Figure copyright Kriss Wittmann. All rights reserved. Used by permission. 
spent, and teams function. Community-owned and -operated residencies will give family medicine the power to develop excellent personal physicians and create a true medical home for their patients.

\section{Five Principles of Residency Transformation}

We propose five principles to guide the redesign and transformation of family medicine residency programs.

\section{Place and Structure:}

\section{Family Medicine Residencies}

Will Be Community-Based, and Owned and Operated Through a Network of Reliable Partnerships Since the 1960s, community hospitals and academic medical centers have sponsored most family medicine residency programs. Medicare and Medicaid funding for education has been directed primarily to hospitals, with hospital-affiliated service by residents as a justification. The current sponsorship and financing of residency education constrains residency programs' innovation and limits their ability to create local, community-responsive patient care and education.

Sponsorship of new family medicine residency programs should transition from health system-owned to community-owned organizations encompassing a diverse mix of local clinical practice sites (eg, federallyqualified health centers [FQHCs], system-owned practices, clinicianowned practices, and innovative health care delivery models such as direct care practices). The organizations should be nonprofit foundations, educational corporations, or similar entities located in and named for a local place-a meaningful group of neighborhoods, communities, and/or habitats with recognized ties, troubles, and traditions. Community-owned residency organizations will implement, administer, and assume accountability for educating residents and other trainees and establishing collaborative governance and contractual partnerships with appropriate collaborating local practices. Work on the nature and sustainability of partnerships, ${ }^{7}$ collaborative governance models, ${ }^{8}$ and formal relational contracting ${ }^{9}$ provide a framework for selecting optimal governance and contracting for each local situation. Partnerships with local hospitals, skilled nursing facilities, community organizations, and educational facilities will also be necessary.

The residency will be managed by a governing board with representatives of local practice sites, community partnerships, and patients. The board will recruit and select the residency program director and residency manager, who appoint/hire educators and staff. With assistance from the residency organization, practice sites will develop a formal patient/community engagement strategy guided by patients, community leaders, specialty physicians/clinicians, residents, and other health professions students. We suggest each clinic have a community advisory committee to review challenges, make suggestions, and raise patient concerns..$^{10,11} \mathrm{FQHCs}$, also known as community health centers, are community-based, patient-directed primary care practices, many of which are long-time residency partners, and help demonstrate the viability of the proposed collaborations. ${ }^{12,13}$ Implementing this network of partnerships will require a significant investment in building community trust, beginning with transparency, listening, colearning, humility, and willingness to share/release power and control. ${ }^{14}$ Principles of community engagement/mobilization, ${ }^{15,16}$ community-oriented primary care, ${ }^{17}$ and community-based participatory research ${ }^{18}$ are important resources for planning this work.

Programs should have flexibility to develop their own culture of inquiry and learning and modify curricula to fit local/regional circumstances, especially related to social and environmental drivers and equity issues. ${ }^{17,19}$ We recommend flexibility around use of time and length of residency programs. Rather than specify a 3- or 4-year time frame, ${ }^{20,21}$ allow for residency programs to be completed in 2-6 years to accommodate part-time residents and unique learning needs, and to ensure that residents achieve expected competency levels.

Financing. The new residency structure requires implementing the Institute of Medicine's 2014 financing recommendations. ${ }^{22}$ This includes retaining Medicare funds as the primary source of graduate medical education (GME) funding while transitioning to a new system of GME payment and eliminating separate funding streams for direct GME expenditures and indirect costs. Funds would be divided into an operational fund to support existing GME programs and a transformation fund to support innovation and underserved needs. Kaufman and colleagues recommend that the Centers for Medicare and Medicaid Services demand budgetary accountability for GME funds, set national goals to incentivize primary care, and expand funding to support nonhospital venues for primary care residency education..$^{23}$ In addition, we support (1) basing GME payments on a basic per-resident amount, instead of Medicare inpatient days and resident to bed ratio, and (2) directing per-resident funds to institutions responsible for residency educational content (eg, the nonprofit community organizations we describe). Clinical partners, public funding, and philanthropic support, with memoranda of understanding, are also potential sources of support.

\section{Content: Sustain Comprehen- siveness and Generalism (Whole Person ( Family) and Care for Patients Where They Are}

Anchored in the community, family medicine residency education can reimagine the principle of comprehensiveness, of caring for all patients and health issues. It also reaffirms the importance of generalism-caring for patients as whole persons in the context of family, intimate friends, and neighborhoods-including 
understanding patients' goals, cultures, and values.

Comprehensiveness doesn't mean that every residency graduate will engage in the entire scope of clinical care. Rather, every graduate will be comfortable and fluent with language and understanding across the full spectrum of care. Being sufficiently present to the lived experience of full-spectrum care, residents will be comfortable, empathic, and able to guide informed discussions with patients for a range of situations and concerns. In birthing and maternity care, for example, residents must be present with and care for women during pregnancy, while giving birth, and postpartum often and long enough to demonstrate competencies of a sufficient working knowledge, experiential empathy, and professional comfort in ongoing care of pregnant women. ${ }^{24}$ The number of encounters or amount of time in these activities to achieve adequate competency will vary by resident.

Because scope of care and needs change over time, residencies will focus on learning as career-long processes, providing the foundation for ongoing professional development and adaptation to health care system changes and evolving community needs. ${ }^{25}$

Mastery of broad clinical knowledge is essential to care competently for most problems people in communities have most of the time, to respond promptly to urgent needs, and arrange consultations and referrals. While graduates will have a solid understanding of pathophysiology and psychophysiology, social and environmental drivers of health, and mechanisms underlying treatments, the acceleration of highly specialized knowledge makes development of new knowledge platforms to assist in patient care essential. Artificial intelligence, clinical decision support technology, social media, and clinical data warehouses are among the technologies that can assist or detract from patient, population, and community care. ${ }^{4}$
Maintaining a Generalist Mentality. Returning family medicine to the fertile soil of communities can help restore its vitality and connect it to its history. ${ }^{26}$ Future family physicians must know and respect biomedical sciences and their pyramids of evidence. As generalists, they must understand and appreciate the social sciences, arts and humanities, complementary and alternative medicine, cultural healing traditions, and patients' particular capacities, goals, and values. Residents will learn how to adapt to people, personalities, cultures, and communities and to understand and care for families with such tools as genograms and personal genetic information.

Understanding Context. "Caring for patients where they are" implies that residents will learn the value of caring for patients in all settings, eg, hospital, workplace, school, home, nursing home, specialized centers, birthing facilities, virtually, and during life and care transitions ${ }^{27}$ and allow for more purposeful imprinting. ${ }^{28}$ Residents must learn to understand and navigate their community's territory, connecting horizontally across public health, community organizations, and pharmacies, and vertically within health systems, and acquire techniques for advocacy and community engagement. To care for patients wherever they are, residents need to know where patients live, using tools of geographic information services and mapping; how to establish, maintain, and use a registry/panel of patients; and how to link family/household data to guide practice. This will provide a basis for quality improvement projects and practiceand community-based research.

\section{Process: Emphasize Collaborative Learning, Interprofessional Education, and Teams}

Currently, education overemphasizes lectures and top-down teaching. We propose a roundtable model. The image of the roundtable facilitates the trust and safety needed for comprehensive, collaborative, successful learning. ${ }^{29}$ In this context, educators will collaborate with residents and community partners to build trusting relationships, identify learning needs and goals, and design flexible curricula that adapt to learners' characteristics while responding to local community needs. Residents will learn attitudes, skills, and habits that facilitate problemsolving, lifelong reflection, self-assessment, community assessment, and self-guided learning. The roundtable will be used for:

- One-on-one learning;

- Collaborative activities between residents, other health professionals, teachers, and community members, eg, group problem-solving, multi-perspective learning, and case reviews;

- Clinical encounters, where patient and resident gather multiple sources of evidence and information to cocraft a personalized goal-oriented care plan.

Focusing on community and collaborative interprofessional education requires reimagining the role of teacher and faculty ${ }^{30}$ Rather than being institutionally classified, faculty members should reflect community diversity and the multiple ways of knowing that inform generalist practice (Table 1). ${ }^{31}$

Team Care. Participating in interprofessional primary care teams may be the most important roundtable education for residents-an opportunity to learn team-building skills and create high functioning clinical teams in their future practices. ${ }^{32}$ To work well and provide genuine learning, clinical teams need regularly-scheduled time to plan, strategize, and assign responsibilities and review care. ${ }^{33}$ Teams should be flexible, with a core team including faculty, residents, staff, patient/family, and appropriate community educators. Other team members could include behavioral health specialists, social workers, pharmacists, community health workers, dentists, care managers, nutritionists, and health 
Table 1: Residency Faculty/Educators

\begin{tabular}{|c|c|}
\hline Roles & May Be Filled By \\
\hline Practice-based clinicians & $\begin{array}{l}\text { Community-based primary care physicians } \\
\text { Community-based primary care advanced practice clinicians }\end{array}$ \\
\hline Residency-based educators & $\begin{array}{l}\text { Family physicians } \\
\text { Advanced care clinicians } \\
\text { Clinical pharmacists } \\
\text { Behavioral health professionals }\end{array}$ \\
\hline Interprofessional educators & $\begin{array}{l}\text { Social workers } \\
\text { Public health professionals } \\
\text { Midwives }\end{array}$ \\
\hline Selected community members & $\begin{array}{l}\text { Patients } \\
\text { Community leaders } \\
\text { Public officials }\end{array}$ \\
\hline $\begin{array}{l}\text { Adjunct faculty (will engage in } \\
\text { roundtable discussions on clinical topics) }\end{array}$ & $\begin{array}{l}\text { Specialty professionals in highly consulted areas, eg: } \\
\text { - Cardiologists } \\
\text { - Obstetrician-gynecologists } \\
\text { - Orthopedists } \\
\text { - Surgeons } \\
\text { - Physical therapists }\end{array}$ \\
\hline
\end{tabular}

coaches. Patients must learn who is on their team and how they function and contribute. Community practices that successfully integrate care teams should be part of curriculum planning and learner evaluation.

Teams should function like great improvisational jazz ensembles: improving skills, demonstrating trust, and practicing together. ${ }^{34}$ Team roundtables can gather practice and patient data and work with the community to identify important quality improvement projects, particularly those addressing health equity. ${ }^{35}$ Quality improvement in this context refers not to mechanistic plando-study-act cycles, but to learning conversations that embrace the complexity of family medicine and the jazz ensemble skills of sensemaking and action/reflection cycles. ${ }^{36}$ Residency cohorts can use team roundtables to develop and implement community-of-solution projects. ${ }^{37}$

\section{Educators: Develop Local} Family Medicine Educators With National Guidance

Most educators/faculty will need new knowledge, skills, and perspectives for their transformed roles. In preparation for significant changes in residency education, a significant investment must be made in selecting, preparing, and supporting residency role models, guides, mentors, and assessors of residents' work. Residents must become adaptive learners, ${ }^{21} \mathrm{de}$ veloping into clinicians who continue learning and remain current, safe, and effective. Educators must also be highly adaptive, since learners, like patients, have a wide range of cultural, emotional, and experiential backgrounds with varying strengths and needs.

Faculty education must be built on trust, including opportunities for educators to practice new skills and reflect on and learn from their experiences in a supportive environment. A successful transition will require committed faculty with the essential attitudes and capabilities to educate residents within the new structure. New content, processes, and location of education will challenge educators to adapt and learn new methods of teaching. Faculty and educator development must begin early and should be available throughout their careers.

Effective faculty development will adapt to their backgrounds, previous experiences, and program role(s). Faculty members need opportunities to develop and enhance skills in creating trusting relationships that help residents set learning goals, reflect on/learn from their experiences, engage in self-assessment, invite feedback, practice new skills and ways of being, and much more. Learning roundtable education and implementing competency-based assessment ${ }^{38,39}$ requires extensive time and continuing investment. National organizations committed to education, such as the Society of Teachers of Family Medicine (STFM), Association of Departments of Family Medicine (ADFM), and the Association of Family Medicine Residency Directors (AFMRD), should expand and continue to develop innovative approaches to faculty development.

\section{Coordination/Evaluation/ \\ Accountability: Create \\ Bioregional Collaboratives}

Residency organizations will participate in bioregional collaboratives, presently a missing infrastructure for most residencies, that will share resources among residencies and be responsible for equity, educational support, and educational and organizational accountability. All residencies in the bioregion will be represented. The term "bioregion" encompasses climate and ecology along with history, cultures, and political features. A bioregion is where economy, society, and environment, 
including climate change, intersect to cocreate health..$^{40-42}$ Collaboratives will function as professional learning communities where ideas are shared, vetted, and encouraged. ${ }^{43}$ They will provide ongoing evaluation and assessment of their residency organizations, providing formative feedback for programs and faculty members. Evaluation will include comparative assessment of member residencies and sharing educational and clinical innovations. Collaboratives can assist residency programs in defining goals and expectations and recommend progress toward accreditation based on achieving those goals. Diversity within collaboratives will enable rich health care and educational research.

Over time, collaboratives will create the social and professional fabric for a bioregion's family medicine community and could tightly connect with other state- and regional-level programs, such as primary care extension services ${ }^{44}$ and practice-based research networks (PBRNs). ${ }^{45}$ PBRNs, in turn, will help initiate community-based participatory research that informs bioregional practices and residencies about assets and needs and engages community stakeholders as equal partners in making social/environmental change for better health and greater equity ${ }^{46}$ Collaboratives will also be a resource for teaching procedures, arranging resident electives, and offering tutors, mentors, coaches, and apprenticeships. They will work with programs and graduates to create a bioregional practice and teaching community that assists in residency education and expedites lifelong learning and ongoing connection of graduates to their residency.

\section{A Pathway to Transformation}

While these principles and ideas are not new, ${ }^{17}$ implementing them-refocusing family medicine residency education on communities and collaboration-would be. They are consistent with burgeoning efforts by residencies across the country, recommendations from a recent summit on redesigning family medicine residencies ${ }^{47}$ the American Medical Association's efforts to accelerate changes in medical education, ${ }^{48}$ and recent recommendations by the Health Resources and Services Administration's Advisory Committee on Training in Primary Care Medicine and Dentistry. ${ }^{49}$ They are already being fueled by rising commitments to address social and environmental determinants of health and relieve unconscionable inequities.

Making this vision a reality requires a pathway to begin and sustain the work of transformation. This includes a posture of humility and a welcoming stance toward willing partners including community leaders, medical and surgical specialists, health professionals, and policy makers committed to preparing outstanding personal physicians for individual and community health and well-being.

We propose declaring 2022-2032 the "Decade of Family Medicine Residency Transformation," capitalizing on the immediate opportunity to incorporate into new family medicine residency accreditation standards an approved pathway with great flexibility to innovate. Assets can be mobilized to advance this transformation. Specifically:

1. The Accreditation Council on Graduate Medical Education (ACGME) and American Board of Family Medicine (ABFM) could invite family medicine residencies in good standing to apply to join an initial cohort of 50-75 demonstration sites. The cohort would learn together, over 10 years, how to redesign their educational programs, report progress annually, and participate in an externally-funded implementation evaluation that includes their graduates. All other family medicine residency programs would be encouraged to begin moving in these directions as they are able.

2. The ABFM Foundation and AFMRD could jointly fund a mixed-methods evaluation team, including education and practice change facilitators embedded within demonstration sites and their regional collaboratives. The evaluation would provide close to real-time feedback loops to guide rapid-cycle innovation work.

3. National family medicine organizations and their allies could prioritize rejuvenating Title VII of the Public Health Service Act funding designated to support residencies' transformation plans, replicating a critical strategy that helped initiate family medicine residencies in the 1970's.

4. STFM, AFMRD, ADFM and other academic organizations could sponsor robust faculty development programs to prepare and engage interprofessional faculty and educators for revised roles in adaptive resident education.

5. Policy centers and health-oriented foundations addressing primary care or health care workforce could focus on transforming payment policy for primary care practices and family medicine residencies. A steady stream of policy briefs should connect demonstration sites with evolving national and state health policy developments, while regional collaboratives provide new findings to be translated and shared with decision-makers. Centers and foundations could also serve critical roles in cultivating interprofessional, interdisciplinary, and intersectoral collaborations.

6. NAPCRG could convene Starfield Summits to provide national exposure of successes and challenges to the private and public sectors and government officials and representatives.

By working together and mobilizing assets such as these, transformation of family medicine residencies is possible, now. 


\section{Discussion}

The family medicine residency structure we envision will turn its gaze toward the places where residency graduates will practice and the world in which they will live. Residencies will become critical community institutions, strengthening human and social connections and promoting cooperative relationships over time. They will teach clinical and operational competencies, modeling partnerships and teamwork for excellent clinical care, and promote continuous learning beyond residency. As with all new enterprises, this requires an environment that permits implementation, time, and investment sufficient to pay for transitions and revised operations.

Residency programs sponsored and overseen by community and professional governance will continuously assess challenges and successes and enable scaling up of programs nationwide. More programs in more regions will help demonstrate the value of collaboration, data sharing, and joint learning, leading to better quality and more effective education.

The central goal of this transformation is to produce excellent community-focused personal physicians, ${ }^{50}$ broadly-educated expert generalist ${ }^{51}$ who establish and sustain ongoing, trusting relationships with patients over time and across place. As clinically-competent, trusted partners and advisors who understand patients' goals and life circumstances, personal physicians provide, or work with others to provide, health care services that patients want and need. This requires the ability to work collaboratively to integrate physical, mental, and social needs; practice community engagement, strategic planning, clinical flexibility and team care; meet public/community health needs; adopt an expansive vision of primary care functions and facilitators ${ }^{6}$; and practice humility in the face of patients' lives and cultures. ${ }^{52}$ Indeed, the personal physician represents a critical shift from reductionism and fragmentation to generalism and integration (Table
2). This challenging role can be deeply satisfying. It is best learned, we believe, in supportive, communitybased programs where residents, faculty, and community partners work together toward personal, broadbased health.

Graduates will not only be excellent personal physicians. They will be change agents, experienced in the emerging responsibilities of primary care to extend and engage care in communities through public health, community organizations, and government alliances, and in organizing practices for change, a coevolution of education and practice. ${ }^{19}$ They will bring approaches they learn in residency-practicing and learning in teams, working with community members, engaging in outreach-to their own practices. To be competitive in recruiting family medicine graduates, health systems will be motivated to adopt the working conditions and relationships in which residents have learned. Transforming education, then, will create a generation of family physicians who

Table 2: Critical Shifts in the Perspectives of Personal Physicians

\begin{tabular}{|l|l|l|l|}
\hline \multicolumn{2}{|c|}{ Transition From } & Collaboration & $\begin{array}{l}\text { Working in partnership to set and meet } \\
\text { patients' health goals }\end{array}$ \\
\hline Paternalism & Knowing better than others & Person focus & Focus on caring for whole people \\
\hline Disease focus & Focus on treating diseases & $\begin{array}{l}\text { Health care } \\
\text { focus }\end{array}$ & Preserving and restoring health \\
\hline Intervention focus & Saving lives & $\begin{array}{l}\text { Championship } \\
\text { team }\end{array}$ & Jazz ensemble \\
\hline Cheroic physician & Lone ranger & Fulfilling needs & $\begin{array}{l}\text { Focus on what is often immeasurable: } \\
\text { relationships, fulfilling diverse needs }\end{array}$ \\
\hline Reductionism & Focus on what is measurable & $\begin{array}{l}\text { Focus on small parts and pieces } \\
\text { that may lose relevance for overall } \\
\text { health }\end{array}$ & Generalism \\
Fragmentation & $\begin{array}{l}\text { Splicing health care into many } \\
\text { silos aligned with professional } \\
\text { specialties and disciplines }\end{array}$ & Integration & $\begin{array}{l}\text { Uniting the disciplines and specialties of } \\
\text { medical, behavioral, mental, and public } \\
\text { health }\end{array}$ \\
\hline Producing inequities & $\begin{array}{l}\text { Fragmented care aggravates } \\
\text { challenges of cost, access, and } \\
\text { equity }\end{array}$ & $\begin{array}{l}\text { Reducing } \\
\text { disparities }\end{array}$ & $\begin{array}{l}\text { Serves as common integrating source of } \\
\text { care for all }\end{array}$ \\
\hline Commercialism & Profit, wealth, and competition & Professionalism & Service, health, and collaboration \\
\hline Hospital ownership & $\begin{array}{l}\text { Ownership of primary care } \\
\text { practices and top-down } \\
\text { management }\end{array}$ & $\begin{array}{l}\text { Hospital } \\
\text { partnership } \\
\text { primary care practices to engage in } \\
\text { person- and community-aligned behavior }\end{array}$ \\
\hline
\end{tabular}


will, by example, drive the transformation of primary care practice.

\section{Conclusion}

In 1979, Gayle Stephens described family medicine as "counterculture," in part because of the value it placed on patients' life experiences and the immersion of family physicians in their communities rather than academic medical centers. He called on family medicine to "rethink the priorities of medical education on the basis of the medical needs of the public rather than on the basis of preserving the professional selfinterest of organized medicine." ${ }^{53}$ If family medicine takes this exhortation to heart, adapting residency education to community needs and reclaiming its patient advocacy role, if we work to continuously understand the effects of this approach on health care, clinicians, and communities, it will finally be the adaptive counterculture that Stephens envisioned, with innovation and experimentation as the norm, not the exception.

CORRESPONDING AUTHOR: Address correspondence to Robin S. Gotler, Center for Community Health Integration, Case Western Reserve University School of Medicine, 11000 Cedar Ave., Ste. 402, Cleveland, OH $44106-$ 3069.216-368-3887.rsh@case.edu.

\section{References}

1. Eliot TS. Little Gidding. London, England: Faber \& Faber; 1942.

2. Newton WP, Magill M, Biggs W, et al. Re-envisioning family medicine residencies: the end in mind. J Am Board Fam Med. 2021;34(1):246-248. doi:10.3122/jabfm.2021.01.200604

3. Newton WP, Mitchell KB, Magill MK. The future of family medicine residency education: the specialty has spoken. Ann Fam Med. 2021;19(2):185-187. doi:10.1370/afm.2677

4. Newton WP, Mitchell K. Reenvisioning family medicine residency education. Fam Med. 2021;53(7):487-489.

5. Implementing high-quality primary care: rebuilding the foundation of health care. Washington, DC: National Academies of Science, Engineering and Medicine; 2021.
6. Bazemore A, Grunert T. Sailing the 7C's: Starfield revisited as a foundation of family medicine residency redesign. Fam Med. 2021;53(7):506-515.

7. Mitchell SM, Shortell SM. The governance and management of effective community health partnerships: a typology for research, policy, and practice. Milbank Q 2000;78(2):241-289, 151. doi:10.1111/14680009.00170

8. Proulx K, Hager M, Klein K. Models of collaboration between nonprofit organizations. Int J Prod Perform Manag. 2014;63:746-765. doi:10.1108/IJPPM-06-2013-0121

9. Frydlinger D, Hart O, Vitasek K. A New Approach to Contracts. Harvard Business Review. September-October 2019. https:// hbr.org/2019/09/a-new-approach-to-contracts. Accessed August 1, 2021.

10. Sharma AE, Knox M, Mleczko VL, Olayiwola JN. The impact of patient advisors on healthcare outcomes: a systematic review. BMC Health Serv Res. 2017;17(1):693. doi:10.1186 s12913-017-2630-4

11. Lehmann C, Liao W. The patient voice: participation and engagement in family medicine and residency education. Fam Med. 2021;53(7):578-579.

12. . Morris CG, Johnson B, Kim S, Chen F. Training family physicians in community health centers: a health workforce solution. Fam Med. 2008; 40(4): 271-6.

13. Chen C, Chen F, Mullan F. Teaching health centers: a new paradigm in graduate medical education. Acad Med. 2012;87(12):1752-1756 doi:10.1097/ACM.0b013e3182720f4d

14. Wallerstein N, Muhammad M, SanchezYoungman S, et al. Power dynamics in community-based participatory research: a multiple-case study analysis of partnering contexts, histories, and practices. Health Educ Behav. 2019;46(1_suppl): 19S-32S. doi:10.1177/1090198119852998

15. Clinical and Translational Science Awards Consortium Community Engagement Key Function Committee Task Force on the Principles of Community Engagement. Principles of Community Engagement. Second edition. Bethesda, MD: National Institutes of Health; June 2011. http://www.atsdr.cdc.gov/communityengagement/pdf/PCE_Report_508_FINAL.pdf

16. Wallerstein N, Minkler M, Carter-Edwards L, Avila M, Sanchez V. Improving health through community engagement, community organization, and community building. In: Glanz K, Rimer BK, Viswanath K, eds. Health behavior: theory, research, and practice. San Francisco, CA: Jossey-Bass; 2015:277-300.

17. Nutting PA, ed. Community-Oriented Primary Care: From Principle to Practice. Washington, DC: US Government Printing Office; 1987.
18. Wallerstein N, Duran B, Oetzel J, Minkler M. Community-Based Participatory Research for Health: Advancing Social and Health Equity. 3rd ed. San Francisco, CA: JosseyBass; 2018.

19. Wheat S. Community: the heart of family medicine. Fam Med. 2021;53(7):528-531.

20. Douglass AB. The case for the 4-year residency in family medicine. Fam Med. 2021;53(7):599-602.

21. Woolever DR. The case for 3 years of family medicine residency training. Fam Med. 2021;53(7):603-605.

22. Eden J, Berwick D, Wilensky G, eds. Committee on the Governance and Financing of Graduate Medical Education. Graduate medical education that meets the nation's health needs. Washington, DC: National Academies Press; 2014.

23. Kaufman A, Scott MA, Andazola J, Fitzsimmons-Pattison D, Parajón L. Social accountability and graduate medical education. Fam Med. 2021;53(7):632-637.

24. Barr WB. Women deserve comprehensive primary care: the case for maternity care training in family medicine. Fam Med. 2021;53(7):524-527.

25. Edje L, Price DW. Training future family physicians to become master adaptive learners. Fam Med. 2021;53(7):559-566.

26. Roberts DW. Health is a community affair. Preview of the final report of the National Commission on Community Health Services. JAMA. 1966;196(4):332-333. doi:10.1001/ jama.1966.03100170074022

27. Kahn NB Jr. Redesigning family medicine training to meet the emerging health care needs of patients and communities: be the change we wish to see. Fam Med. 2021;53(7):499-505.

28. Phillips RL Jr, Holmboe ES, Bazemore AW, George BC. Purposeful imprinting in graduate medical education: opportunities for partnership. Fam Med. 2021;53(7):574-577.

29. Westberg J, Jason H. Collaborative clinical education: the foundation of effective health care. New York: Springer; 1993.

30. Arenson C, Brandt BF. The importance of interprofessional practice in family medicine residency education. Fam Med. 2021;53(7):548-555.

31. Jabbarpour Y, Westfall J. Diversity in the family medicine workforce. Fam Med. 2021;53(7):640-643.

32. Margolius D, Bodenheimer T. Transforming primary care: from past practice to the practice of the future. Health Aff (Millwood). 2010;29(5):779-784. doi:10.1377/ hlthaff.2010.0045

33. Sinsky CA, Bodenheimer T. Powering-up primary care teams: advanced team care with in-room support. Ann Fam Med. 2019;17(4):367-371. doi:10.1370/afm.2422 
34. Haidet P, Jarecke J, Yang C, Teal CR, Street RL, Stuckey H. Using jazz as a metaphor to teach improvisational communication skills. Healthcare (Basel) 2017;5(3):41. Published 2017 Aug 4. doi:10.3390/healthcare5030041

35. Elliott TC. How do we move the needle?: building a framework for diversity, equity, and inclusion within graduate medical education. Fam Med. 2021;53(7):556-558.

36. Miller WL, Crabtree BF, Nutting PA, Stange KC, Jaén CR. Primary care practice development: a relationship-centered approach. Ann Fam Med. 2010;8(suppl 1):S68-S79, S92. doi:10.1370/afm.1089

37. Gotler RS, Green LA, Etz RS. What 1966 can teach us about the future of primary care: the case for communities of solution. Milbank Q Opinion. Published June 10, 2020 Accessed June 14, 2021. https://www.milbank.org/quarterly/opinions/what-1966-canteach-us-about-the-future-of-primary-carethe-case-for-communities-of-solution

38. Holmboe ES. The transformational path ahead: competency-based medical education in family medicine. Fam Med. 2021;53(7):583589 .

39. Saultz J. Competency-based education in family medicine residency education. Fam Med. 2021;53(7):590-592.

40. Church SP. Exploring urban bioregionalism: a synthesis of literature on urban nature and sustainable patterns of urban living. S.A.P.I.EN.S. 2014;7(1). Accessed August 1, 2021. http://journals.openedition.org/sapiens/1691

41. Lynch T, Glotfelty C, Armbruster K, eds. The Bioregional Imagination: Literature, Ecology, and Place. Athens, GA: University of Georgia Press, 2012.
42. Carr M. Bioregionalism and Civil Society: Democratic Challenges to Corporate Globalism (Sustainability and the Environment 9). Vancouver, Canada: UBC Press (University of British Columbia); 2005.

43. Stange KC. Holding on and letting go: a perspective from the Keystone IV Conference. J Am Board Fam Med. 2016;29(suppl 1):S32S39. doi:10.3122/jabfm.2016.S1.150406

44. Ono SS, Crabtree BF, Hemler JR, et al. Taking innovation to scale in primary care practices: the functions of health care extension. Health Aff (Millwood). 2018;37(2):222-230. doi:10.1377/hlthaff.2017.1100

45. Green LA, Hickner J. A short history of primary care practice-based research networks: from concept to essential research laboratories. J Am Board Fam Med. 2006;19(1):1-10. doi:10.3122/jabfm.19.1.1

46. Tremblay MC, Martin DH, McComber AM, McGregor A, Macaulay AC. Understanding community-based participatory research through a social movement framework: a case study of the Kahnawake Schools Diabetes Prevention Project. BMC Public Health 2018;18(1):487. doi:10.1186/s12889-0185412-y

47. Family Medicine. Volume 53, Issue 7. Accessed October 1, 2021. https://journals.stfm. org/familymedicine/2021/july-august/

48. Accelerating Change in Medical Education. American Medical Association. https://www. ama-assn.org/education/accelerating-changemedical-education. Accessed June 11, 2021.
49. Advisory Committee on Training in Primary Care Medicine and Dentistry. Innovations in Primary Care Education and Training Developing Community Partnerships to Improve Population Health. Rockville, MD: Health Resources and Services Administration; October 2020. Accessed October 1, 2021. https://www.hrsa.gov/sites/default/files/hrsa/ advisory-committees/primarycare-dentist/ reports/actpcmd-17-report.pdf

50. Phillips RL Jr, Brundgardt S, Lesko SE, et al. The future role of the family physician in the United States: a rigorous exercise in definition. Ann Fam Med. 2014;12(3):250255. doi:10.1370/afm.1651

51. Reeve J, Beaulieu MD, Freeman T, et al. Revitalizing generalist practice: the Montreal statement. Ann Fam Med. 2018;16(4):371373. doi:10.1370/afm.2280

52. Berwick DM. The epitaph of profession. Br J Gen Pract. 2009;59(559):128-131. doi:10.3399/bjgp08X376438

53. Stephens GG. Family medicine as counterculture. Fam Med. 1989;21(2):103-109. 